\title{
Springtime Onset of Isolated Convection Precipitation across the Southeastern United States: Framework and Regional Evolution
}

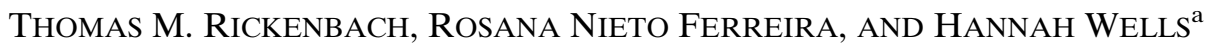 \\ Department of Geography, Planning and Environment, East Carolina University, Greenville, North Carolina
}

(Manuscript received 23 August 2019, in final form 21 November 2019)

\begin{abstract}
This study examines the geographic and temporal characteristics of the springtime transition to the summer precipitation regime of isolated convection in the southeastern (SE) United States during 2009-12, using a high-resolution surface radar-based precipitation dataset. Isolated convection refers herein to isolated elements or small clusters of precipitation in radar imagery less than $100 \mathrm{~km}$ in horizontal dimension. Though the SE United States does not have a monsoon climate, it is useful to apply the established framework of monsoon onset to study the timing and regional variation of the onset of the summer isolated convection regime. Overall, isolated convection rain onset in the SE U.S. domain occurs in late May. Onset begins in south Florida in mid-April, continuing nearly simultaneously across the southeastern coastal plain in early to midMay. In the northern domain, from Virginia to the Ohio Valley, onset generally occurs much later (mid-June to early July) with more variable onset timing. The sharpness of onset timing is most evident in the coastal plain and Florida. Results suggest the hypothesis, to be examined in a forthcoming study, that the timing of isolated convection onset in the spring may be triggered by specific synoptic-scale events within gradual seasonal changes in atmospheric conditions including extratropical cyclone tracks, convective instability, and the westward migration of the North Atlantic subtropical high. This approach may offer a useful framework for evaluating long-term changes in precipitation for subtropical regimes in an observational and modeling context.
\end{abstract}

\section{Introduction}

The southeastern (SE) United States experiences ample precipitation year-round, about $100 \mathrm{~mm} \mathrm{month}^{-1}$ on average since the late nineteenth century (NOAA/NCEI 2019). Embedded within the relatively flat annual cycle of precipitation is a clear summer maximum in rain from isolated convection (Rickenbach et al. 2015), typically with the spatial and diurnal characteristics of airmass thunderstorms. Isolated convection refers herein to precipitation organized as isolated elements or small clusters with associated radar pattern less than $100 \mathrm{~km}$ in horizontal dimension (Rickenbach et al. 2015), that is, less than mesoscale in size (Houze 1989). Accordingly, isolated convection as defined here represents a similar

\footnotetext{
${ }^{a}$ Current affiliation: Cooperative Institute for Mesoscale Meteorological Studies, University of Oklahoma, and NOAA/NWS Warning Decision Training Division, Norman, Oklahoma.
}

Corresponding author: Thomas M. Rickenbach, rickenbacht@ ecu.edu but more general categorization than pulse thunderstorms (Miller and Mote 2017), which are restricted to groups of thunderstorms associated with severe weather in a weakly forced synoptic environment. Superficially, the seasonal cycle of isolated convection rain in the SE United States resembles the annual precipitation evolution of a monsoon. However, while the hallmark of a classical monsoon is a well-defined wet and dry season, the summer convective season in the SE United States instead emerges from changing seasonal characteristics of precipitation systems that occur all year. The annual progression of precipitation regimes in the SE United States include frontal rain and mesoscale convective systems associated with extratropical cyclones that occur year-round (Geerts 1998; Curtis 2006; Feng et al. 2019), isolated thunderstorms in the warm season (Wallace 1975; Winkler et al. 1988; Brooks and Stensrud 2000), and tropical cyclones in late summer and fall (Larson et al. 2005; Zhou and Matyas 2017). These regimes overlap considerably, influenced by a seasonal evolution of interacting forcing mechanisms including the position of the midlatitude jet stream and associated 
extratropical (ET) cyclone track (Zishka and Smith 1980; Nieto Ferreira et al. 2013), the annual cycle of SSTs ( $\mathrm{Li}$ et al. 2017), and the intensification and westward migration of the North Atlantic subtropical high (NASH) (Henderson and Vega 1996; Li et al. 2011; Zhu and Liang 2013).

Although the summer convective season in the SE United States is not a monsoon, it is useful to consider established mechanisms of monsoon onset since both regimes share certain aspects of seasonal evolution, in particular the onset timing and regional variation. In the Indian monsoon, precipitation advances northward in late spring (Fasullo and Webster 2003; Noska and Misra 2016) associated with the poleward migration of the ITCZ, and modulated by a seasonal large-scale thermally direct land-ocean circulation (Ramage 1971). Arrival of the precipitation associated with the migrating ITCZ marks the onset of the monsoon. Regional variants of the classical monsoon, such as in Southeast Asia and South America, emphasize the role of tropicalextratropical interactions in the timing and geographic pattern of monsoon onset. In Southeast Asia, the extension of a stalled extratropical frontal zone (the mei-yu front) into the subtropics often inaugurates the monsoon season, typically in May (Lau and Yang 1997; Yihui and Chan 2005). The establishment of the South Atlantic convergence zone (SACZ), a stationary extratropical frontal region extending into the tropical Amazon basin, is the key to triggering springtime monsoon onset in subtropical South America (Garreaud 2000; Raia and Cavalcanti 2008; Nieto Ferreira and Rickenbach 2011). In these regions, monsoon onset is generally rapid and well defined, resulting from the gradual increase in solar insolation in conjunction with a rapid dynamical trigger. Regional monsoon onset in South America is typically defined by attainment and sustained exceedance of a precipitation threshold appropriate to the annual precipitation climatology (Marengo et al. 2001). In the SE United States, isolated convection is driven by thermodynamic instability common in the warm season, though large-scale circulations such as jet stream trough and ridge patterns influence favorable conditions (Byers and Braham 1948; Wallace 1975; Maddox and Doswell 1982). Mesoscale convection generally requires dynamical forcing often in association with forced frontal ascent that may or may not be associated with thermodynamic instability (Harrold 1973; Rasp et al. 2016). Radar analyses for the SE United States suggest a summertime increase in heavy precipitation (Fabry et al. 2017) and radar echo frequency (Carbone and Tuttle 2008) in the coastal region with a strong afternoon diurnal maximum, a trend which Rickenbach et al. (2015) associate mainly with isolated convection.

Rickenbach et al. (2015) applied a size-based criterion to 4 years of instantaneous radar observations of contiguous precipitation features in the SE United States, as a simple proxy to distinguish between precipitation features smaller than $100 \mathrm{~km}$ in horizontal dimension and those greater or equal to $100 \mathrm{~km}$. The $100 \mathrm{~km}$ size threshold corresponds to the minimum size of a mesoscale convective system (MCS), which is a specific type of mesoscale precipitation feature with a leading line of convection and associated stratiform rain (Leary and Houze 1979; Houze 1989). Rickenbach et al. (2015) found a clear warm season maximum in rain from isolated precipitation features (hereafter IPF), while precipitation from mesoscale precipitation features (hereafter MPF) was relatively constant from season to season. Their approach established that the IPF framework is useful to study diurnal to seasonal changes in isolated convection. This objective framework is designed to distinguish mesoscale from smaller-scale precipitation features using a simple, easily reproducible approach, independently of ambient environmental conditions, time evolution of features, heavy rain thresholds, associated severe weather, or combining multiple datasets. Other studies objectively analyzed rain systems to identify MCS in reflectivity maps (Geerts 1998; Haberlie and Ashley 2019; Feng et al. 2019), geostationary infrared satellite images (Machado et al. 1998; Carvalho and Jones 2001), or combined radar and passive microwave satellite measurements (Nesbitt et al. 2000; Rickenbach et al. 2011). These studies applied a combination of size, shape, duration or intensity algorithms to identify MCS based on criteria outlined in Houze (1989) for the construction of regional climatologies and case studies. Carbone et al. (2002) examined the propagation characteristics of radar-observed rain features in the continental United States over several years, and inferred the presence of MCS based on duration and size in a time-distance depiction. The weakly forced (pulse) thunderstorm climatology of Miller and Mote (2017) used composite reflectivity maps to identify heavy raining convective cells, tracked in time, and sorted as to storm environment. In the framework of the present study, phenomena such as pulse thunderstorms and MCS are subsets of the broader categories of IPF and MPF.

This paper builds upon the radar-based precipitation analysis of Rickenbach et al. (2015), focusing on the spring to summer transition of IPF rain in the SE United States for 2009-12 to address the following questions. Does the warm season onset of IPF precipitation in the SE United States progress poleward like a classical 

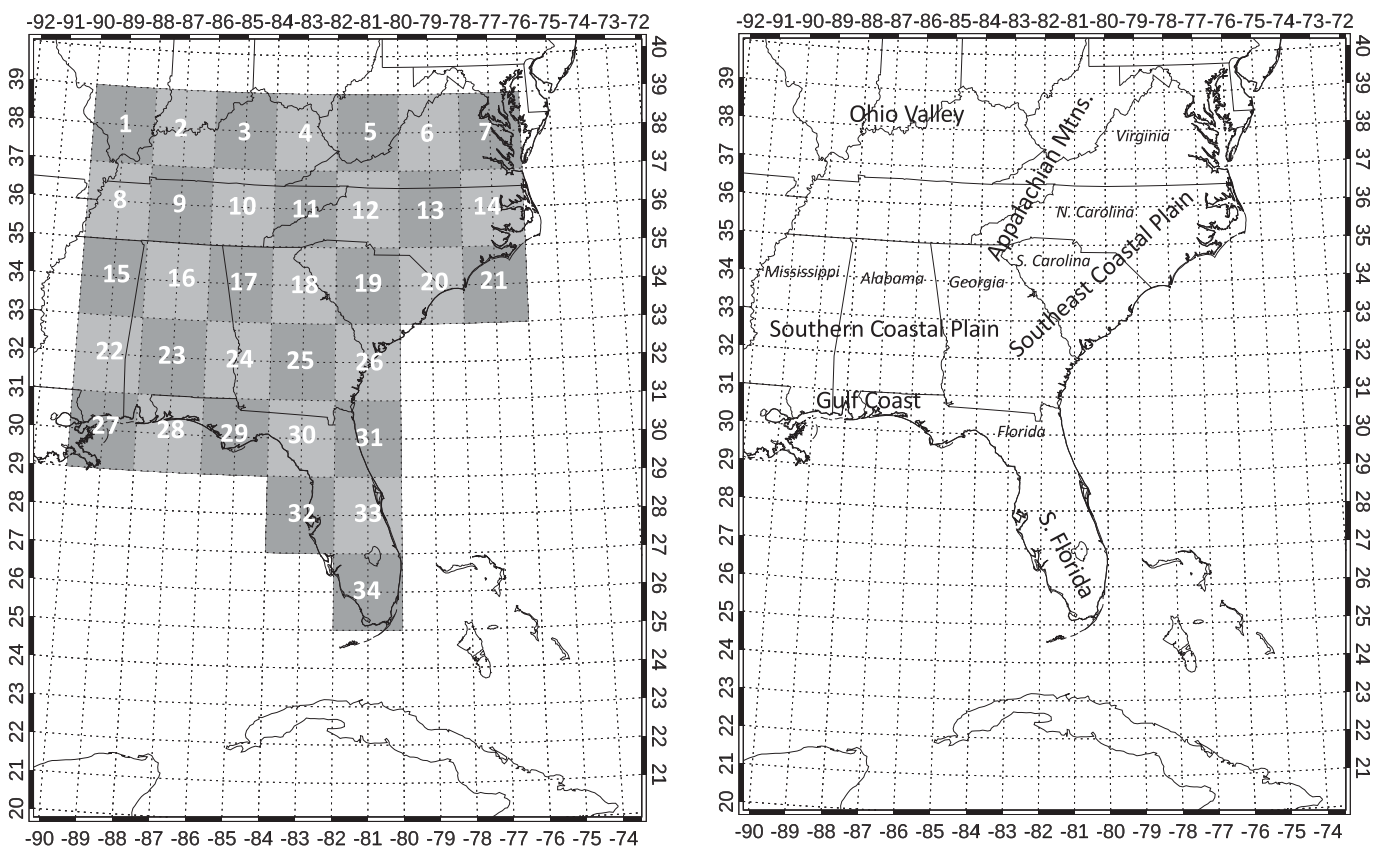

FIG. 1. The SE U.S. study region. (left) Numbered $2^{\circ} \times 2^{\circ}$ boxes covering the analysis domain, and (right) state names (italicized) and geographic regions (plain font) discussed in the paper.

monsoon? Is IPF onset gradual over several weeks, or rapid over several days similar to monsoon onset? What are the regional characteristics of IPF onset timing? Are these behaviors consistent year to year?

By applying monsoon concepts to examining the onset of the summer precipitation regime, this paper establishes a useful framework for a forthcoming study of the large-scale mechanisms controlling the annual cycle of the isolated convection season in the SE United States. This approach may also aid in the evaluation of long-term changes in regional precipitation (past and future) of the SE United States and other mixed subtropical regimes in the context of observational and high-resolution modeling studies.

\section{Methodology}

The precipitation data used in this study is derived from the high-resolution radar-based National Mosaic and Multi-Sensor Quantitative Precipitation Estimation dataset (NMQ; Zhang et al. 2011), extracted from the national mosaic for the SE United States. The NMQ dataset was derived from the national network of Next Generation Weather Radar (NEXRAD), assembled on a $0.01^{\circ} \times 0.01^{\circ}$ grid (roughly $1 \mathrm{~km} \times 1 \mathrm{~km}$ ), constructed and archived at the NOAA/National Centers for Environmental Information (NCEI). The current version of this precipitation dataset, the Multi-Radar Multi-Sensor (MRMS) Reanalysis from NEXRAD quantitative precipitation estimates (QPEs), is available at NOAA/NCEI (https://data.nodc.noaa.gov/cgibin/iso?id=gov.noaa.ncdc:C01543). This dataset was used in a 4-yr study (2009-12) of mesoscale and isolated precipitation organization for the SE United States (Rickenbach et al. 2015). As in that study, all rain features less than $100 \mathrm{~km}$ in maximum dimension were objectively identified in instantaneous images as IPF, with the remainder as MPF using the $100 \mathrm{~km}$ size threshold of an MCS (Houze 1989). A rain feature is defined as a contiguous group of pixels with instantaneous rain rate greater than or equal to $0.5 \mathrm{~mm} \mathrm{~h}^{-1}$, corresponding to light rain. Rickenbach et al. (2015) show examples of IPF and MPF feature identification results for both summer and winter precipitation events.

The IPF and MPF features are identified in instantaneous rain maps each hour for the 4 -yr dataset spanning 2009-12. Precipitation is then summed at each pixel to produce maps with daily values for IPF, MPF, and total precipitation. High-resolution monthly maps of IPF precipitation, averaged over the 4 years, are constructed from the daily values. Pentad averages of daily precipitation for the IPF and MPF categories are determined within each of 34 (total) $2^{\circ} \times 2^{\circ}$ box regions. From these pentad values, time series of IPF precipitation for each year and all years combined are produced for each box and for all boxes combined. Shown in Fig. 1 is the array of boxes (numbered 1-34) defining the SE U.S. domain used in the analysis, along with geographic regions 
TABLE 1. Lookup table of pentad dates during spring and summer.

\begin{tabular}{cc}
\hline Pentad number & Date range \\
\hline 19 & $1-5$ Apr \\
20 & $6-10 \mathrm{Apr}$ \\
21 & $11-15 \mathrm{Apr}$ \\
22 & $16-20 \mathrm{Apr}$ \\
23 & $21-25 \mathrm{Apr}$ \\
24 & $26-30 \mathrm{Apr}$ \\
25 & $1-5 \mathrm{May}$ \\
26 & $6-10$ May \\
27 & $11-15$ May \\
28 & $16-20$ May \\
29 & $21-25$ May \\
30 & $26-30$ May \\
31 & 31 May-4 Jun \\
32 & $5-9$ Jun \\
33 & $10-14$ Jun \\
34 & $15-19$ Jun \\
35 & $20-24$ Jun \\
36 & $25-29$ Jun \\
37 & 30 Jun-4 Jul \\
38 & $5-9$ Jul \\
\hline
\end{tabular}

referenced in the paper including south Florida, the Gulf Coast, the southern and southeastern coastal plain, the Appalachian Mountain region, and the Ohio Valley. Table 1 provides the dates of the 5-day period corresponding to each pentad number from April to July, the months spanning the onset season.

The determination of IPF rain onset pentad in each $2^{\circ} \times 2^{\circ}$ box is based on the methodology of Marengo et al. (2001), Liebmann and Marengo (2001), and Nieto Ferreira and Rickenbach (2011) established for studies of regional patterns of the South America monsoon onset. Onset timing is determined at each box based on IPF rain exceeding a threshold value and remaining above it for a sufficient period. The choice of a single threshold based on the regional average was demonstrated in the aforementioned studies to tie the seasonal evolution of onset in South America more directly to the seasonal migration of the intertropical convergence zone. The onset threshold value is defined to be the 2009-12 IPF average rain rate over the SE U.S. domain (Fig. 1), which was $0.76 \mathrm{~mm} \mathrm{day}^{-1}$. The sensitivity of onset timing to variations in this threshold is discussed in section 4. For each year, the time series of pentadaveraged IPF rain values of a given box was searched starting with the first value of the year. The first pentad to have met the following two criteria were identified as the onset pentad. First, the IPF rain value had to equal or exceed the onset threshold. Second, five of the eight subsequent pentad IPF rain values were required to be greater than or equal to the threshold. This second criterion ensured that IPF rain onset represented a sustained increase rather than a transient peak in rainfall, accounting for the inherent variability of precipitation. Each year, the onset pentads for each box are determined from the box-averaged time series. Similarly, the 2009-12 average time series is used to find the mean onset pentads at each box. The overall onset pentad for the entire SE U.S. domain is determined for each year, and for all years combined, from time series averaged over all boxes.

\section{IPF rain onset evolution: 4-yr mean}

Although IPF precipitation in the SE United States is a relatively small fraction $(22 \%)$ of the total, the seasonal averages have a distinct annual cycle (Table 3 ). The relative amount of IPF precipitation for the 2009-12 average progresses seasonally from a DJF minimum of $8 \%$ to a JJA maximum of $39 \%$. The $2009-12$ mean annual cycle of pentad-averaged precipitation for the SE United States (Fig. 2) demonstrates a clear summer maximum in IPF precipitation embedded within a variable but relatively trend-free annual variation in MPF and total precipitation. Outside of the summer season, MPF precipitation is particularly variable, consistent with the association of MPF in winter almost exclusively with the frontal zones of transient ET cyclones (Rickenbach et al. 2015). The mean IPF precipitation increases fairly steadily from about pentad 22 (midApril) to a maximum around pentad 42 (late July). During the springtime increase, the IPF onset criteria applied to this time series diagnosed an onset date of pentad 27 (mid-May).

Shown in Fig. 3 are seasonal maps of the percentage of the total precipitation in the IPF category, which indicate the geographic variation of the seasonal progression of IPF relative to the total (IPF + MPF) precipitation. In winter (DJF), IPF precipitation is sparse, generally accounting for less than $10 \%$ of the total for the entire domain, except for $20 \%-40 \%$ IPF in south Florida. This demonstrates that most precipitation is organized on the mesoscale across most of the SE United States in winter. By spring (MAM), the IPF contribution to the total increases somewhat to $20 \%-30 \%$ across the coastal plain and Appalachian Mountain region, while in south Florida a clear maximum of $60 \%-70 \%$ IPF emerges. The summer months (JJA) have a large increase in IPF percentage in those same regions with values from $60 \%$ to $70 \%$ throughout the Appalachian region as well as the southeastern and southern coastal plain. The highest summertime values of IPF rain fraction $(70 \%-80 \%)$ are concentrated in the mountains of western North Carolina, and in the southern tip of Florida. There is a sharp contrast in IPF rain fraction that exactly follows the Gulf Coast and 
2009-2012 Mean Total all boxes

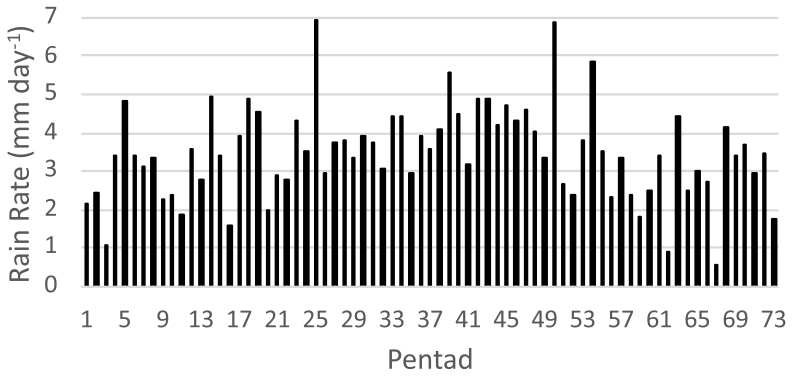

2009-2012 Mean IPF, all boxes

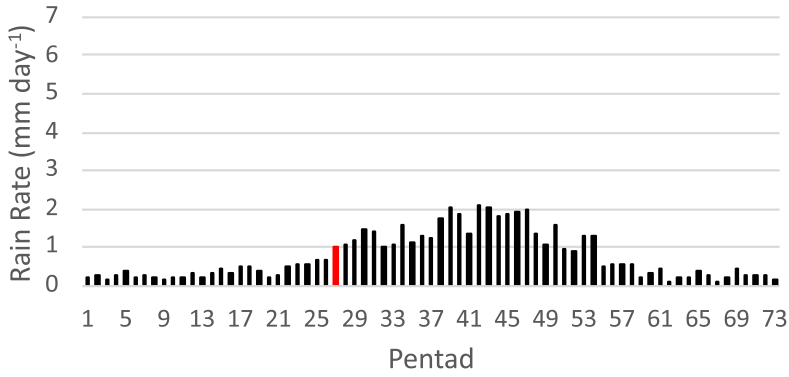

2009-2012 Mean MPF all boxes

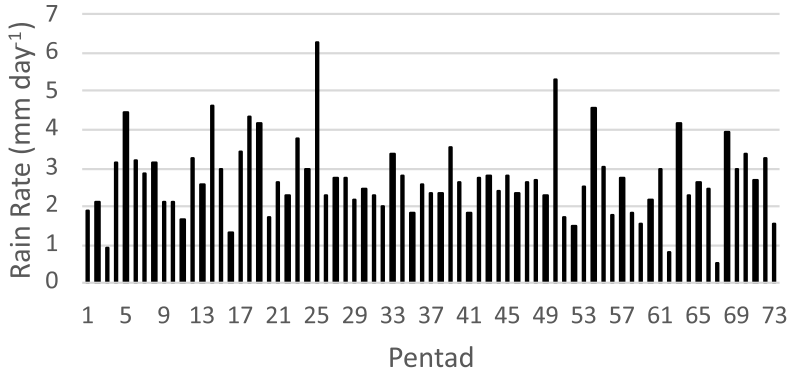

FIG. 2. The 2009-12 averaged pentad-mean seasonal cycle of (top) total rain, (middle) IPF rain, and (bottom) MPF rain for each of the 4 years of the study. The IPF onset pentad is indicated in red. Units are mm day ${ }^{-1}$.

coastal northeastern Florida, with much lower IPF fraction offshore $(20 \%-30 \%)$ compared to inland $(50 \%-70 \%)$, strongly suggesting that a contrast in coastal conditions favors isolated convection onshore and deters it offshore. In the fall (SON), IPF rain percent drops to $10 \%-30 \%$ across most of the domain, but remains similar to the summer values in the Florida panhandle and in the warm surrounding ocean. Figure 3 suggests that summer IPF precipitation is particularly favored in the coastal plain, Appalachian Mountain region, and south Florida. While IPF precipitation accounts for $<10 \%$ of the total in winter north of Florida, it remains an important component of rainfall year-round in south Florida with a summer maximum that extends into fall. These trends are broadly consistent with maps seasonal fraction of mesoscale convective system precipitation shown in Feng et al. (2019).

The 2009-12 monthly averaged maps over the SE United States of IPF rain for the onset transition months of April, May, June, and July are shown in Fig. 4. In April, prior to onset, IPF rain is sparse and weak with no geographic pattern across the domain except for a small region of enhanced IPF rain at the southern tip of Florida. By May, IPF rain increases dramatically especially along the Gulf Coast, southeastern coastal plain, and the Florida peninsula. In June, the coastal contrast of land-based IPF is very clear and remains well defined into July, while IPF rain gradually populates the interior by July. This pattern is also evident in the pulse thunderstorm climatology of Miller and Mote (2017). The highest values are in July along the Gulf Coast of Florida. Note the general north to south gradient of IPF rain by July, with less in the northern domain. The monthly progression indicates a large increase from April to May, consistent with the mid-May overall IPF rain onset timing (Fig. 2).

How does the mean 2009-12 IPF onset timing, and the magnitude of increase in IPF rain post- versus preonset, vary regionally across the SE United States? The onset pentad was determined at each of the 34 (total) $2^{\circ} \times 2^{\circ}$ boxes as described in section 2 . The resulting geographic pattern of onset pentad is shown in Fig. 5a. The range of onset dates in all boxes varied from pentad 22 to 40, or mid-April to mid-July. Onset began in the southern end of the Florida peninsula and at one Gulf Coast box at pentad 22 (mid-April), consistent with the monthly maps shown in Fig. 4. For the southeast coastal plain and Gulf Coast, there was a general tendency for boxes in those regions to have consistent onset timing, with onset between pentad 25-27 (the first half of May). The northwestern domain in the Ohio Valley had the most geographically variable range of onset. The increase from preto postonset IPF rain was measured by the the mean IPF rain rate three months following minus the mean IPF rain rate three months prior to the onset date for each box (Fig. 5b). The greatest increase occurred in the southern coastal plain, Gulf Coast, and southern Florida. The northern boxes, in contrast, had relatively small increases in postonset rain, coinciding with the area of spatially variable onset date. These results suggest that in the southeastern coastal plain and Gulf Coast, IPF rain likely has a common onset mechanism resulting in a consistently timed, large increase in early to mid-May. In the northern domain however, onset timing is highly variable with relatively small difference in post- versus preonset IPF rain, suggesting different mechanisms for IPF onset there. 
a.

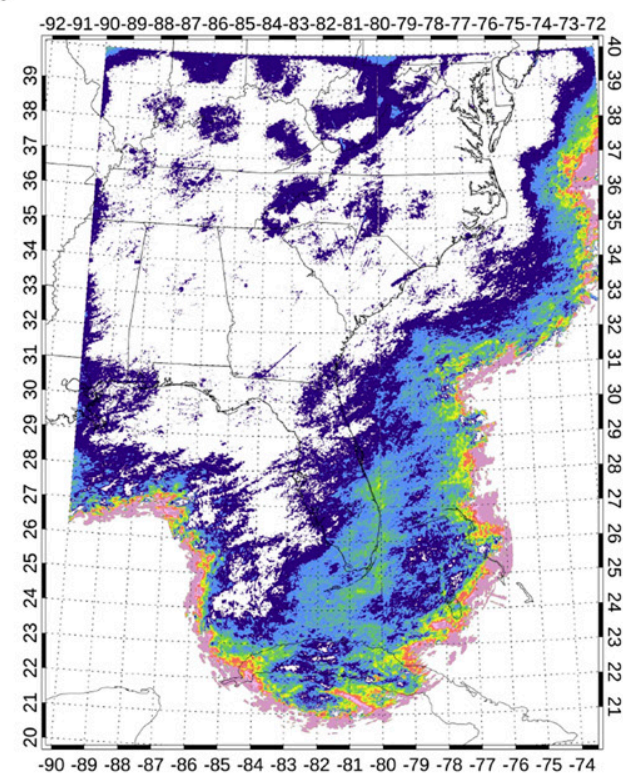

C.

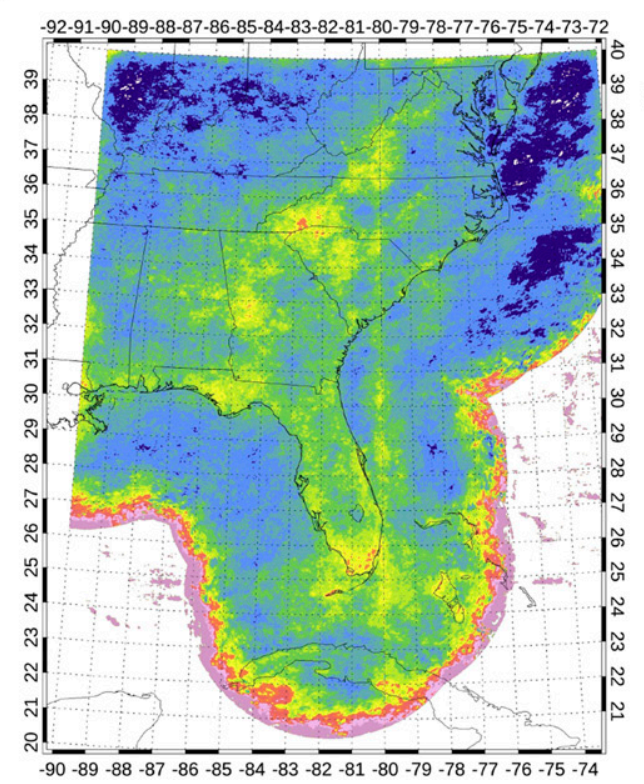

b.

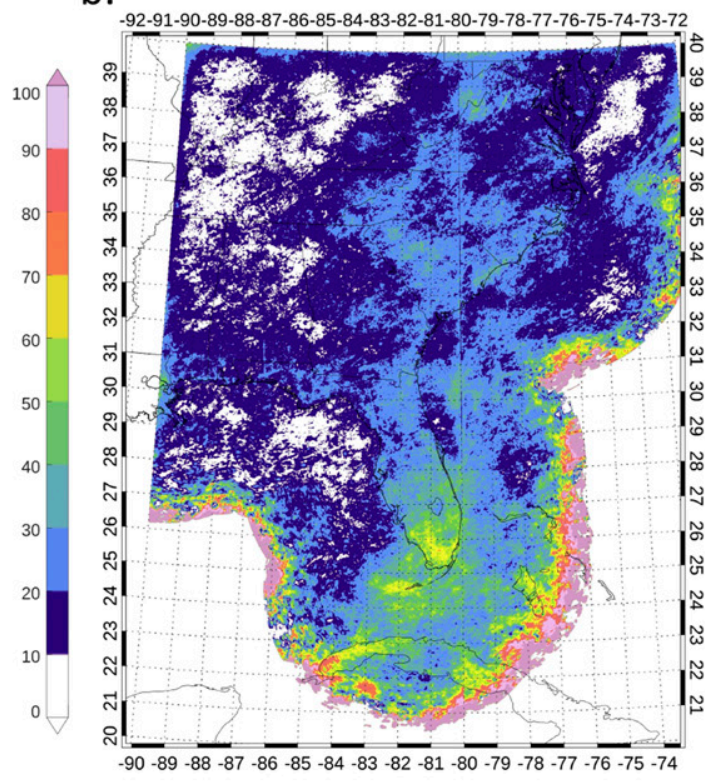

d.

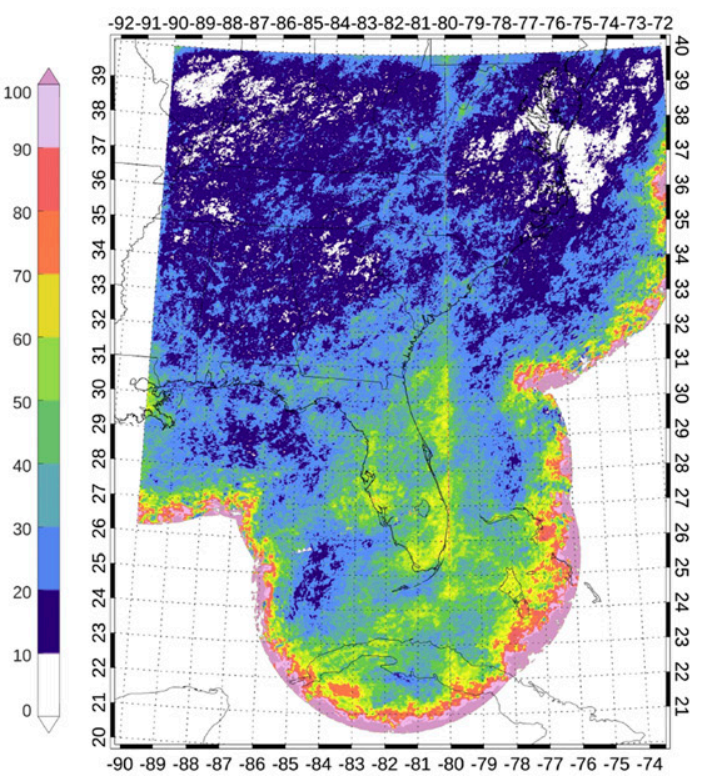

FIG. 3. The 2009-12 seasonal evolution of the percentage of total precipitation in the IPF category, where total is the sum of MPF and IPF, for (a) winter (DJF), (b) spring (MAM), (c) summer (JJA), and (d) fall (SON). At the edge of radar coverage offshore the IPF fraction contain spurious values due to geometric range effects.

The sensitivity of the onset threshold value on the determination of onset pentad was evaluated across a range of threshold values and geographic regions. The rain threshold value of $0.76 \mathrm{~mm} \mathrm{day}^{-1}$ (the "base" threshold) was varied at regular intervals up to $\pm 70 \%$ of the original value. For each threshold interval, the onset pentad determined from the base threshold was subtracted from the onset pentad determined from each threshold interval. This analysis was performed for the 2009-12 average time series, for the overall domain and for four geographically diverse boxes, and is summarized in Table 2. For the full domain time series, changing the rain threshold up to $30 \%$ has no little effect on the onset pentad, with a much greater effect as the threshold is changed more than $50 \%$. A $70 \%$ increase in the rain threshold causes onset to 
a.

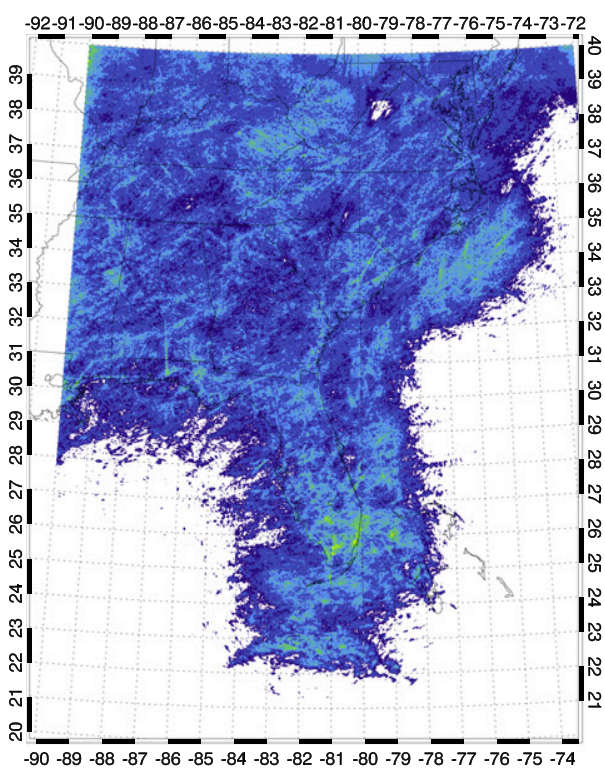

C.

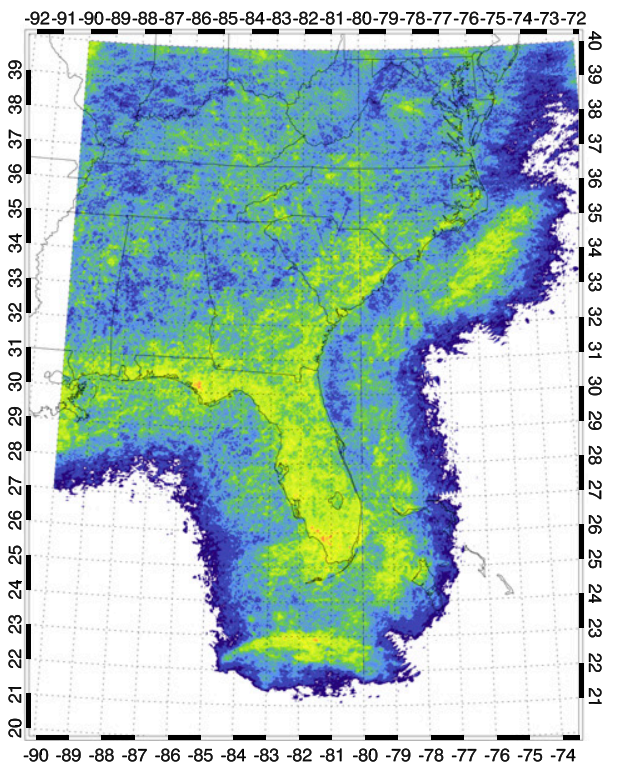

b.

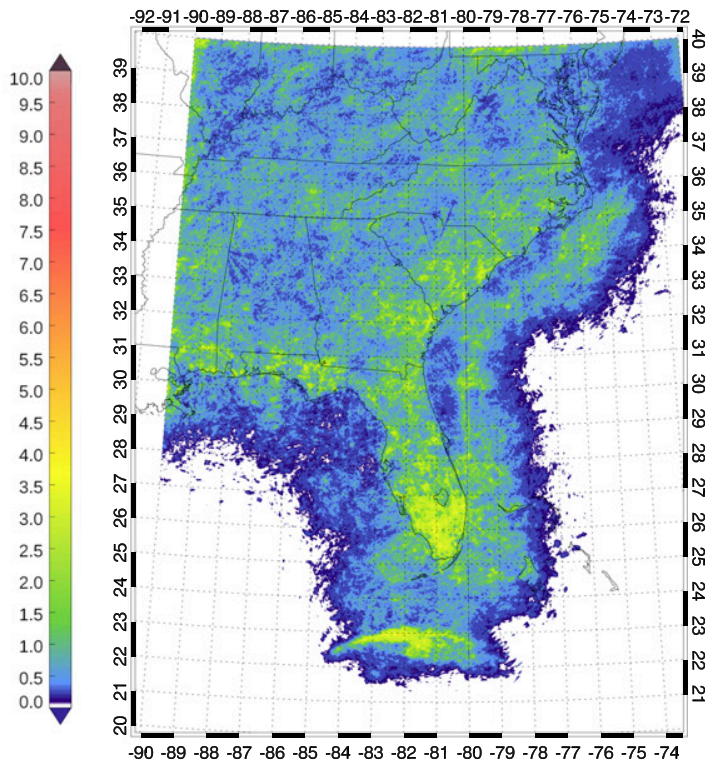

d.

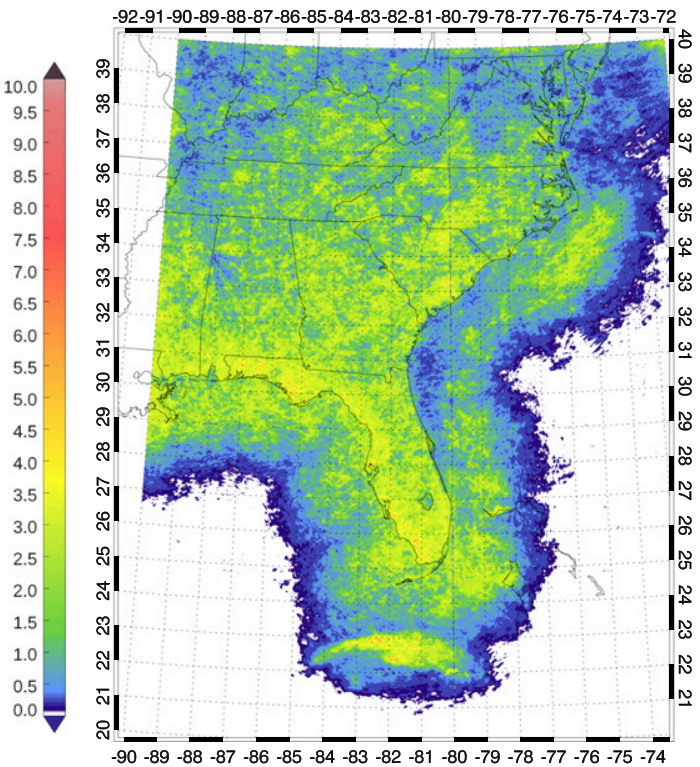

FIG. 4. The 2009-12 monthly averaged IPF rain maps over the SE United States for (a) April, (b) May, (c) June, and (d) July. Units are $\mathrm{mm} \mathrm{day}^{-1}$.

occur 7 pentads later than the base threshold, while a $70 \%$ decrease results in onset 15 pentads earlier. Similar trends occur for the individual boxes, with less sensitivity to threshold changes for the southern boxes (25 and 33) where IPF onset is more abrupt and more clearly defined. For box 2 in the northern domain, where IPF rain is weak and more variable, threshold increase at or above $30 \%$ prevents onset while decreasing the threshold at or below $30 \%$ moves onset 3-5 months earlier.

Is the timing of onset in each box similar for each of the four individual years, that is, do any regions have a consistent onset pentad from year to year? Fig. 5c shows the standard deviation of onset pentad over the 4 years at each box. The lower the standard deviation the more year-to-year consistency in the onset pentad. In general, 
a.

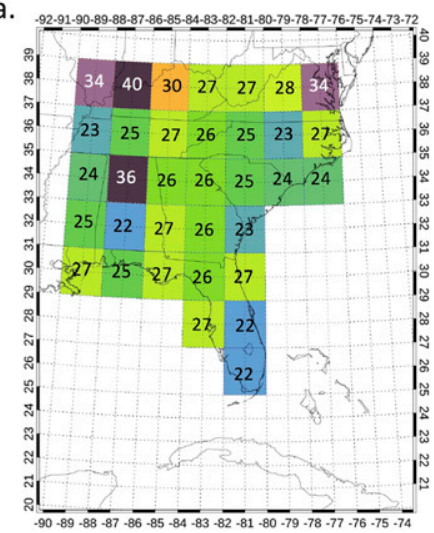

b.

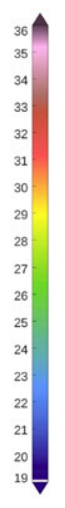

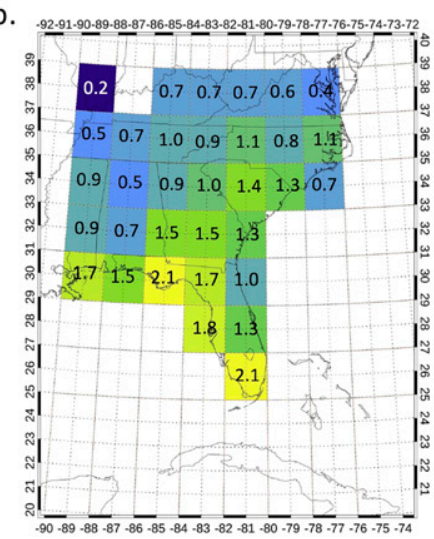

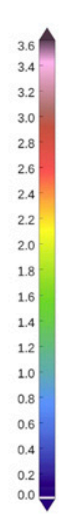

c.

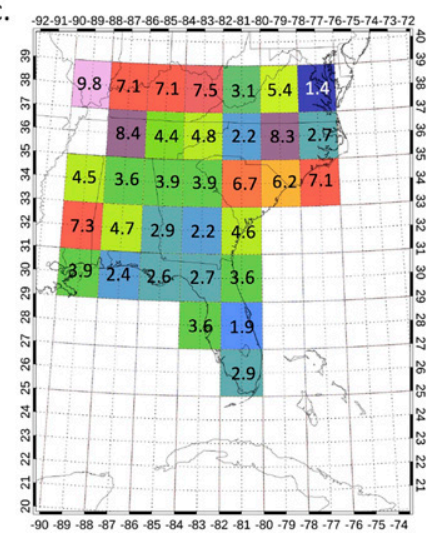

FIG. 5. Onset-related metrics derived from the 2009-12 averaged IPF pentad time series for each analysis box in the SE United States, including (a) onset pentad number; (b) the difference (post minus pre) between the three-month postonset averaged IPF rain rate and the three-month preonset averaged IPF rain rate $\left(\mathrm{mm} \mathrm{day}^{-1}\right)$; and (c) the standard deviation of onset pentad number at each box over the 4 years, with missing box value indicating where only one year met onset criteria. Values are printed in each box and are shown in the corresponding color bar.

the southern domain boxes (coastal plain and Florida) have a more consistent timing of onset, with a standard deviation between 2 and 3 pentads. Farther north, the boxes from the Carolinas to the northwest domain have less consistent onset timing from one year to the next with standard deviation as high as $7-10$ pentads. This suggests that in the southern domain onset is tied to a more consistently timed seasonal mechanism each year, while in the north onset mechanisms may be more variable from year to year.

\section{IPF rain onset evolution: Each year}

This section examines and compares IPF rain onset characteristics each year, to explore further the differences and similarities in the timing and regional variation of IPF onset from year to year. First, an overview comparison of annual and seasonal precipitation (IPF, MPF, and total) for the SE U.S. domain is shown in Fig. 6. The total precipitation annual mean for the entire SE U.S. domain was within about $15 \%$ from year to year, similarly for MPF precipitation. The IPF rain is about one fifth of the total overall, and year-to-year IPF rain ranged by $30 \%$ with the highest value in 2010 and lowest in 2011. The large IPF rain summer maximum seen in the 4-yr mean (Table 3) is also present each year (Fig. 7), with about a 6:1 difference from summer versus winter on average. During 2010 the IPF rain was $25 \%$ above the summer mean, while the MPF precipitation in DJF (winter) of 2010 was about twice as much as each of the other years. The anomalously high winter MPF precipitation that year coincided with the strong El Niño of the 2009-10 winter season, consistent with expectations of above-average winter precipitation in the southern United States during strong El Niño years (Ropelewski and Halpert 1986; Curtis 2006). The pentad-averaged IPF annual cycle over the SE United States is generally similar for each year (Fig. 8) with some differences in onset timing and in pre/postonset variability. Onset dates each year are in May, with the earliest in 2009 (pentad 25, early May) and the latest in 2011 (pentad 30, late May). The springtime onset is particularly sharper in 2009 and 2010, with mean IPF rain increasing dramatically at onset by a factor of 2-3 above all previous values for the year, and a sustained increase each pentad through the summer months.

TABLE 2. Sensitivity of onset pentad on onset rain threshold value for the 2009-12 mean IPF time series. Columns show the difference between the onset pentad determined at threshold values up to $70 \%$ greater than or less than the base threshold value of $0.76 \mathrm{~mm} \mathrm{day}^{-1}$, and the onset pentad determined from the base value (test value minus base value). Results shown for four different box time series and for the all-domain time series.

\begin{tabular}{lcccccrrrr}
\hline \hline & $70 \%$ & $50 \%$ & $30 \%$ & $10 \%$ & $0 \%$ & $-10 \%$ & $-30 \%$ & $-50 \%$ & $-70 \%$ \\
\hline All domain & 7 & 2 & 0 & 0 & 0 & 0 & -4 & -5 \\
Box 33 & 5 & 5 & 5 & 5 & 0 & 0 & 0 & -15 \\
Box 25 & 10 & 2 & 2 & 0 & 0 & -1 & -3 & -7 \\
Box 13 & 15 & 11 & 11 & 0 & 0 & 0 & -14 \\
Box 2 & No onset & No onset & No onset & 0 & 0 & -7 & -17 & -8 & -8 \\
\hline
\end{tabular}




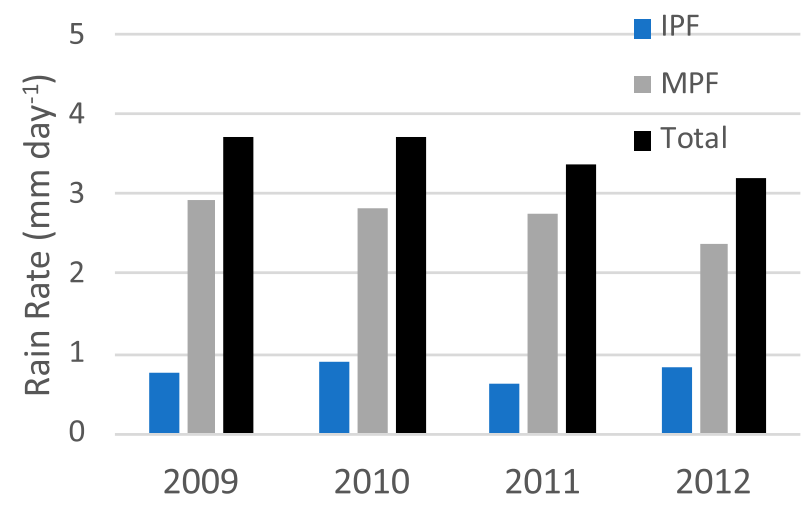

FIG. 6. Annual averaged precipitation $\left(\mathrm{mm} \mathrm{day}^{-1}\right)$ over the SE U.S. domain for each of the 4 years. Shown are IPF (blue), MPF (gray), and total (black) precipitation.

In contrast, the pre- and postonset IPF rain is more variable for 2011 and 2012, with several values of IPF rain exceeding the threshold from six to eight pentads prior to onset in both years. Following onset in 2011, IPF rain decreases to half the onset value for three subsequent pentads before reaching high sustained postonset levels. In 2012, IPF rain decreases notably by pentad 36 (late June) over a month after onset, related to the Gulf Coast landfall of Tropical Storm Debby with associated mesoscale precipitation, to be discussed in a forthcoming study of IPF onset mechanisms.

Maps of the regional variation of IPF onset pentad each year are presented in Fig. 9, along with the postminus preonset IPF rain difference, where "pre" is averaged three months prior to and "post" is three months following onset (similar to Fig. 5). The geographic onset pattern is similar for 2009 and 2010 (Figs. 9a,c), with the following general features. Both years have a large region of simultaneous onset in the southern coastal plain and southern Appalachia, at pentad 25 (early May) in 2009 and pentad 28 (midMay) in 2010. For 2009, onset in south Florida peninsula occurs two pentads following the coastal plain onset, while in 2010 south Florida onset happens two pentads prior. In both years, the spatial pattern of onset in Virginia (northeastern domain) occurs much later, in pentads 34-39 (mid-June to mid-July), compared to the southern region. In general for a given year, onset pentads across the northern domain are much more variable than in the central and southern regions. Several of the boxes in the Ohio Valley (northwestern domain) do not meet the onset criteria for the given year. The post- minus pre-IPF rain difference for 2009 and 2010 (Figs. 9b,d) are quite similar, with much larger rain increases after onset in the southern coastal plain and Florida compared to the
TABLE 3. The 2009-12 seasonal and annual precipitation contribution of IPF and MPF to the total, for the SE U.S. domain.

\begin{tabular}{lrl}
\hline \hline & IPF & MPF \\
\hline DJF & $8 \%$ & $92 \%$ \\
MAM & $16 \%$ & $84 \%$ \\
JJA & $39 \%$ & $61 \%$ \\
SON & $20 \%$ & $80 \%$ \\
Annual & $22 \%$ & $78 \%$ \\
\hline
\end{tabular}

northern domain. In 2011 (Fig. 9e), onset is clearly later than for the other years across most of the domain. The southern coastal plain (southern Alabama and Mississippi) boxes have coincident onset timing in 2011, but about five pentads ( 25 days) later than in 2009 and 2010. The 2011 onset pentads are quite spatially variable in Florida, the southeastern coastal plain, and the northern domain, while onset criteria were not met in the Ohio Valley (northwestern domain). In contrast with the other years, the onset timing in 2012 is highly variable across the entire domain, except for a spatial grouping of onset at pentad 25-26 (early to mid-May) in the Gulf Coast region. Interestingly, the geographic pattern of the mean post- minus pre-IPF rain difference were quite similar each year. That is, all 4 years had larger postminus pre-IPF rain difference in the southern coastal plain and Florida, with small differences in the northern domain. However, the magnitude of the difference, particularly in the southern domain, was less by about a factor of 2 in 2011 and 2012 compared with 2009 and 2010.

To examine the geographic differences in onset timing more closely, the IPF rain pentad annual time series (Figs. 10-13) are compared each year for representative individual boxes (refer to Fig. 1 for box numbers). For south Florida (box 33, Fig. 10), onset pentad timing was the most consistent year to year of all the boxes in the SE U.S. domain, generally pentad 26 or 27 (mid-May) except pentad 30 (late May) in 2011. During 2009 and 2010, the annual time series for box 33 shows a rapid increase at onset with very little IPF rain prior to onset. For 2011 and 2012, onset is not as sharp, with several rainy pentads prior to onset that are followed by minima below the threshold value. Following onset, IPF rain in both years is variable. In fact, all years show "active" and "break" IPF rain periods during the summer months, each lasting anywhere from two to seven pentads. In particular, an IPF rain relative minimum occurs each year in the south Florida box around pentad 39-41 (midlate July) which will be investigated in forthcoming work for a connection with the Caribbean midsummer drought 

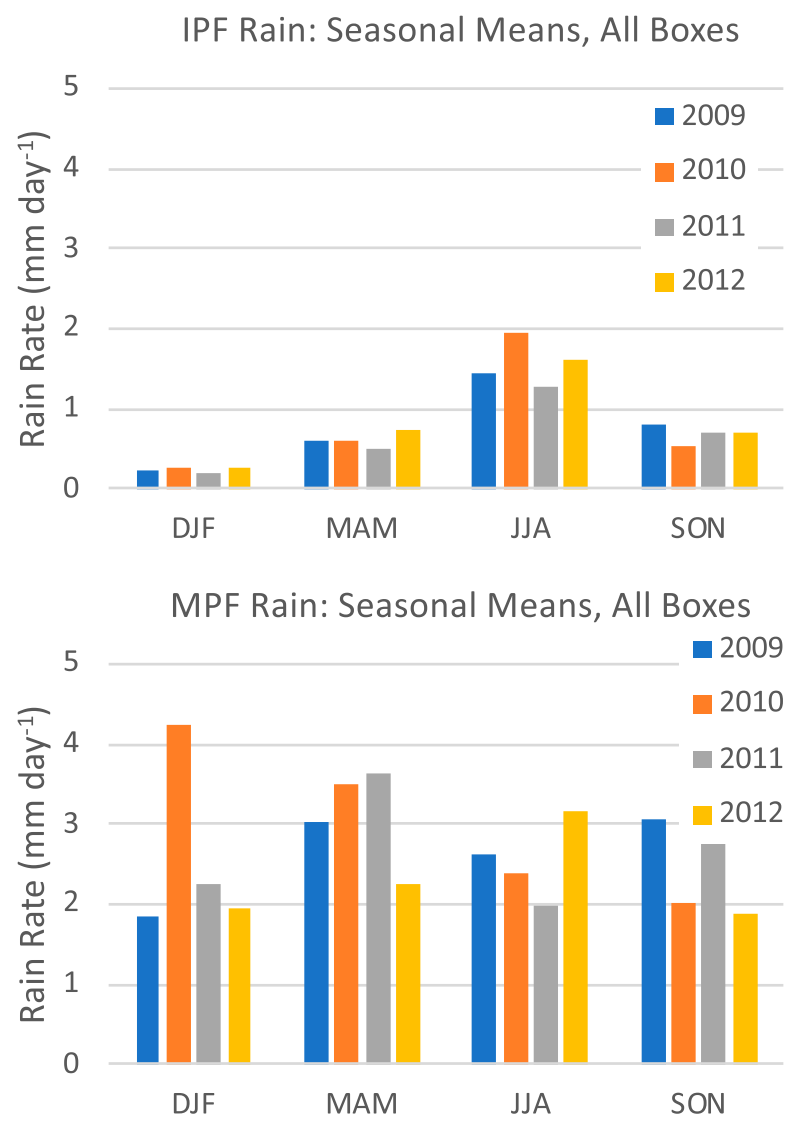

FIG. 7. Three-month averaged seasonal cycle of (top) IPF rain and (bottom) MPF precipitation for each of the 4 years of the study as follows: 2009 (blue), 2010 (red), 2011 (gray), and 2012 (yellow). Units are $\mathrm{mm}_{\text {day }}{ }^{-1}$.

associated with the NASH (Giannini et al. 2000; Gamble et al. 2008). Shown in Fig. 11 are the time series for each year in southern Georgia coastal plain (box 25). In contrast to south Florida, this region has less overall IPF rain, generally more variable and episodic. In no year does the summer IPF rain remain above the threshold value in each pentad following onset. Of note, in 2010, there is an anomalous heavy IPF rain event in the winter season at pentad 5 (21-25 January), associated with the warm sector of a deepening extratropical cyclone traversing the midAtlantic that developed into a Nor'easter off the Carolina coast.

Farther north, in central North Carolina (box 13, Fig. 12), IPF rain is weaker and more variable than the southern boxes. Onset timing is also more variable, ranging from pentad 22 (mid-April) in 2012 to pentad 38 (early July) in 2009. During 2011 in box 13, IPF onset was not attained, since there are enough multipentad periods of low IPF rain when the onset threshold value were not met. In fact IPF rain for box
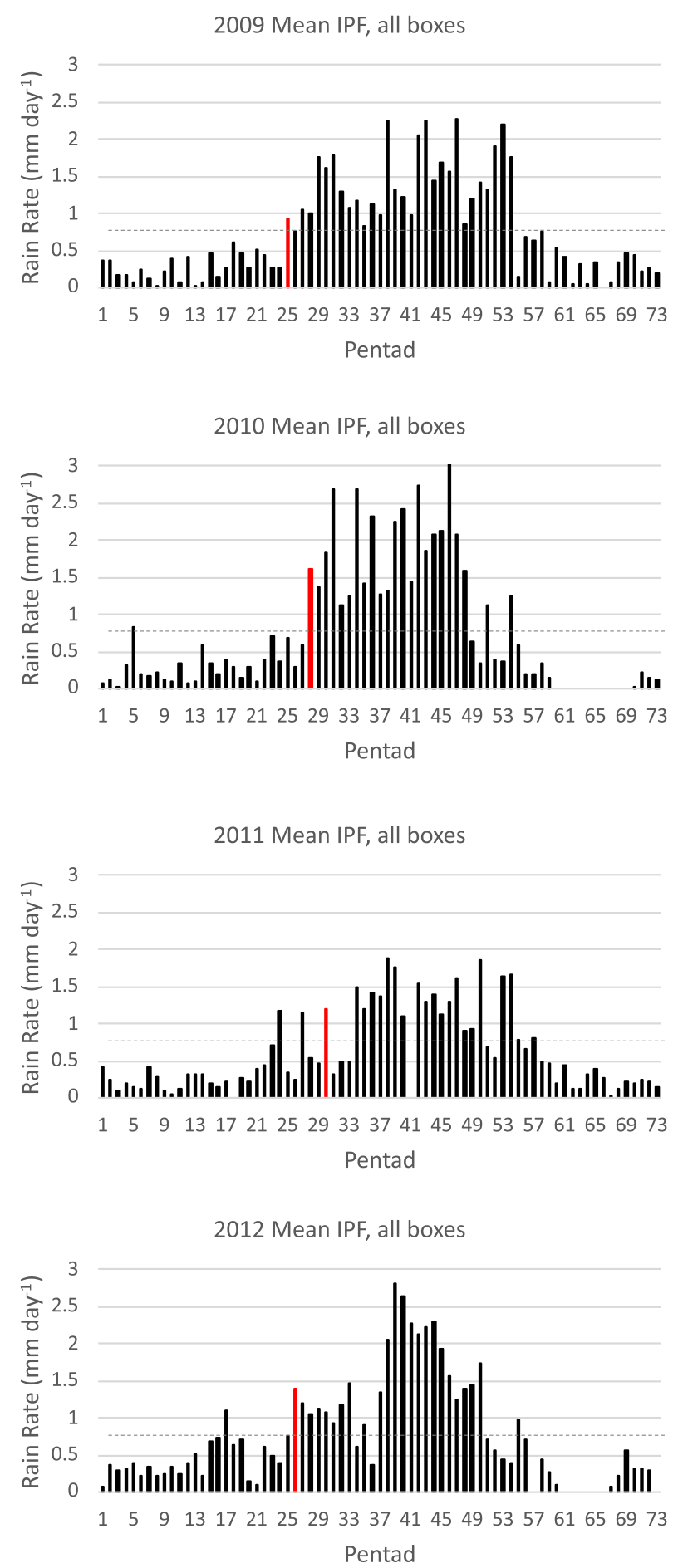

FIG. 8. Pentad-averaged annual cycle of IPF rain $\left(\mathrm{mm} \mathrm{day}^{-1}\right)$ over the SE U.S. domain, for each of the 4 years of the study from (top) 2009 to (bottom) 2012. The IPF onset pentad for each year is indicated in red. The onset threshold value of $0.76 \mathrm{~mm} \mathrm{day}^{-1}$ is shown as a dashed line. 
a.

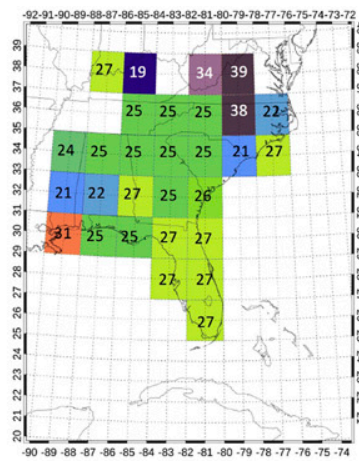

c.

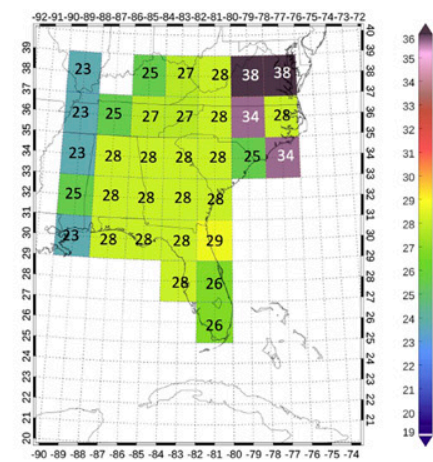

e.

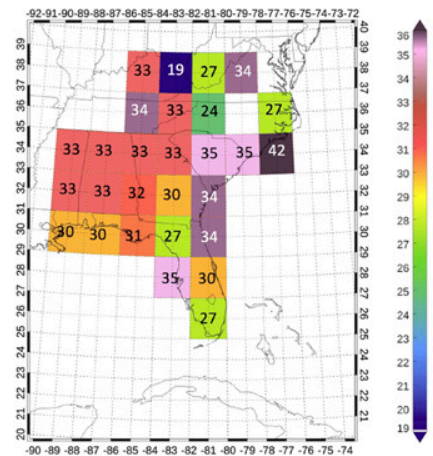

g.

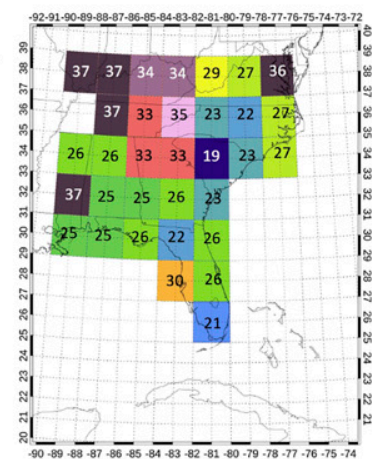

b.

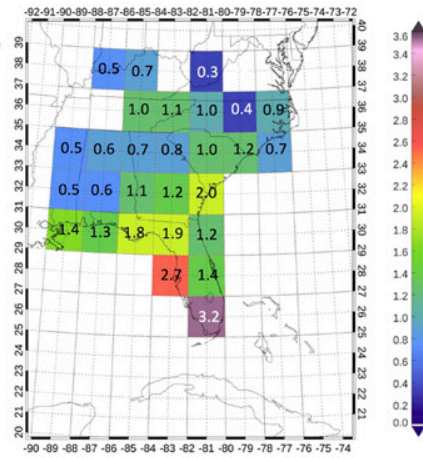

d.

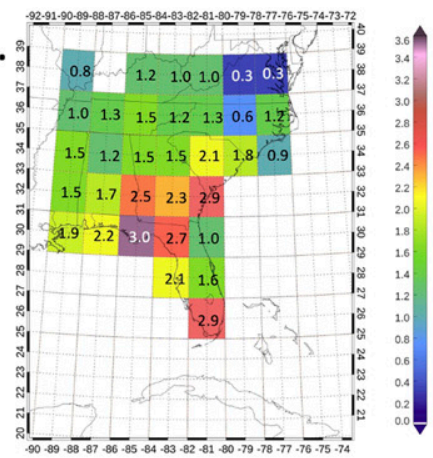

f.

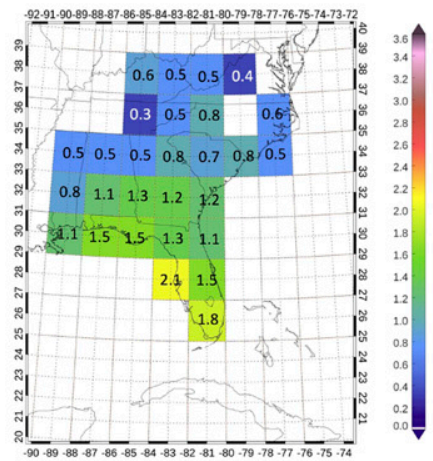

h.

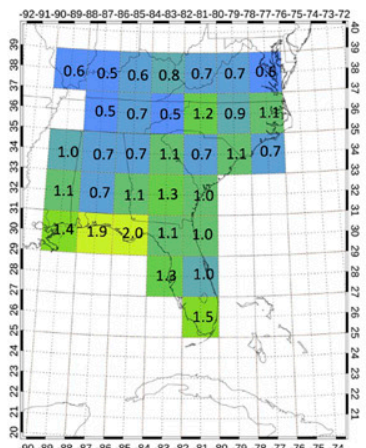

FIG. 9. Onset-related metrics for each year in each analysis box in the SE United States. (left) Onset pentad number and (right) the difference (post minus pre) between the three-month postonset average IPF rain rate and the three-month preonset average IPF rain rate for (a),(b) 2009, (c),(d) 2010, (e),(f) 2011, and (g),(h) 2012. IPF rain difference units are $m m$ day $^{-1}$. Values are printed in each box and are shown in the corresponding color bar. 
2009 IPF, Box33

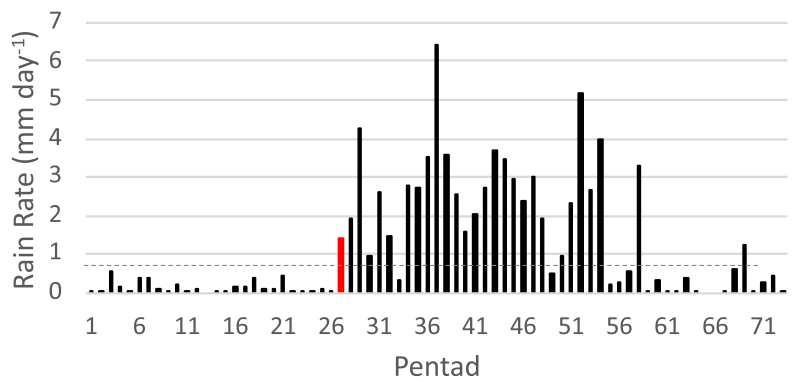

2010 IPF, Box33

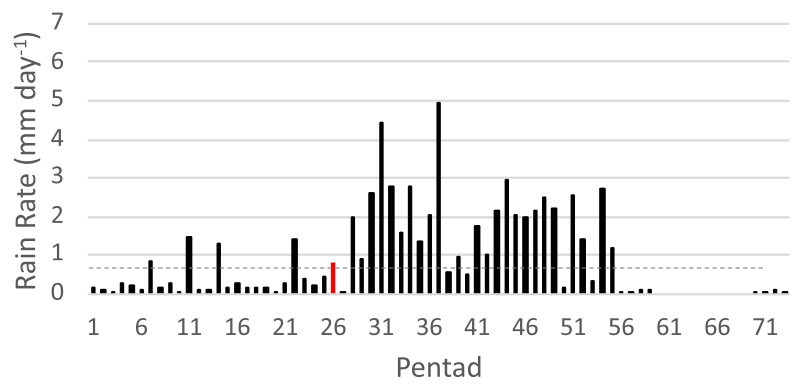

2011 IPF, Box33

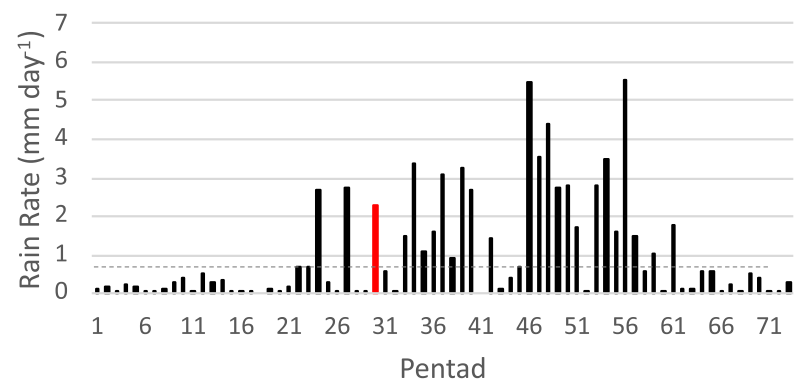

2012 IPF, Box33

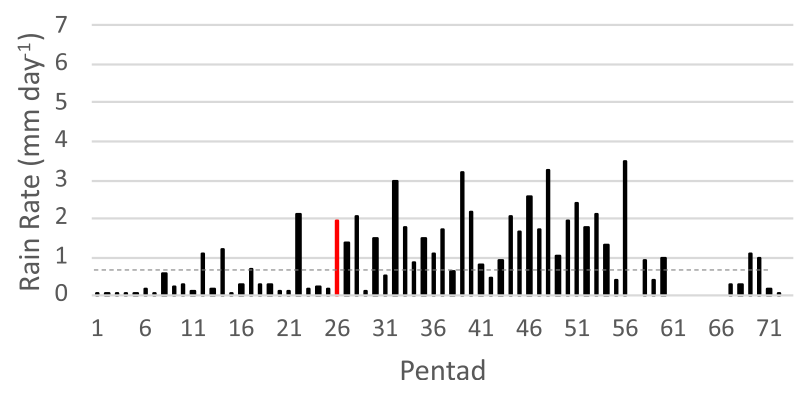

FIG. 10. Pentad-averaged annual cycle of IPF rain $\left(\mathrm{mm} \mathrm{day}^{-1}\right)$ for box 33 (southern Florida peninsula), for each of the 4 years of the study from (top) 2009 to (bottom) 2012. The IPF onset pentad for the box is indicated in red if onset criteria were met for a given year. Onset threshold value of $0.76 \mathrm{~mm} \mathrm{day}^{-1}$ is shown as a dashed line.
2009 IPF, Box 25

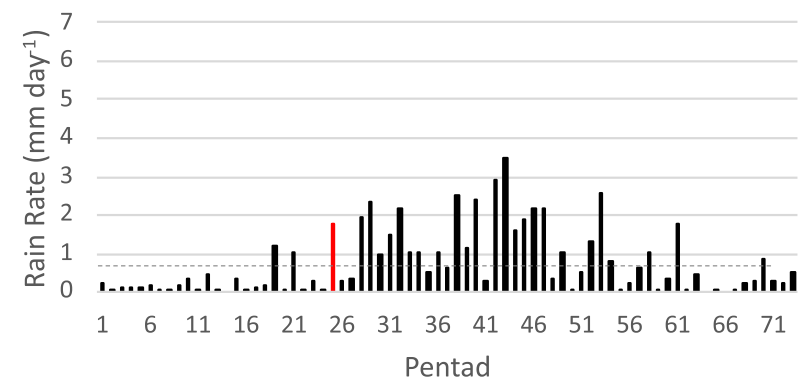

2010 IPF, Box25

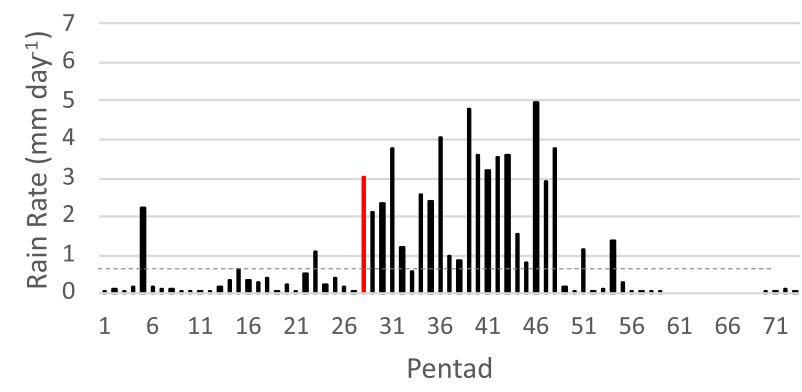

2011 IPF, Box25

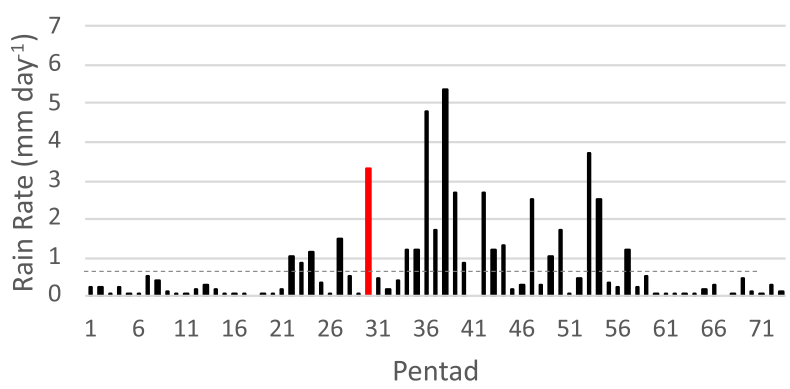

2012 IPF, Box25

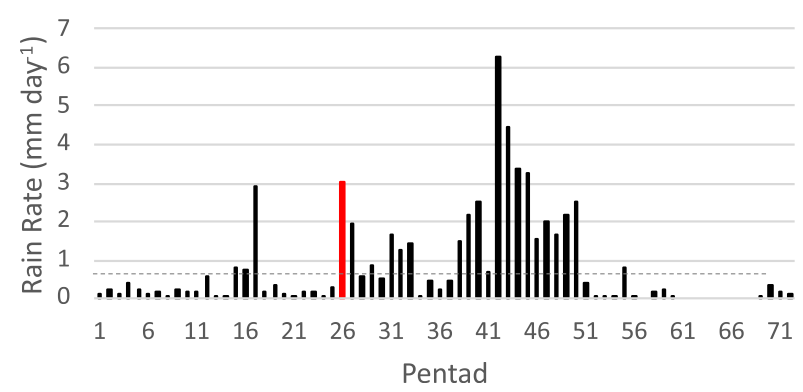

FIG. 11. As in Fig. 10, but for box 25 (south Georgia in the southern coastal plain).

13 only exceeded the threshold value in 11 of the 73 pentads in that year. Finally, in the Ohio Valley in the northwestern domain (box 2, Fig. 13), IPF rain is sufficiently sparse and episodic that onset was 
2009 IPF, Box13

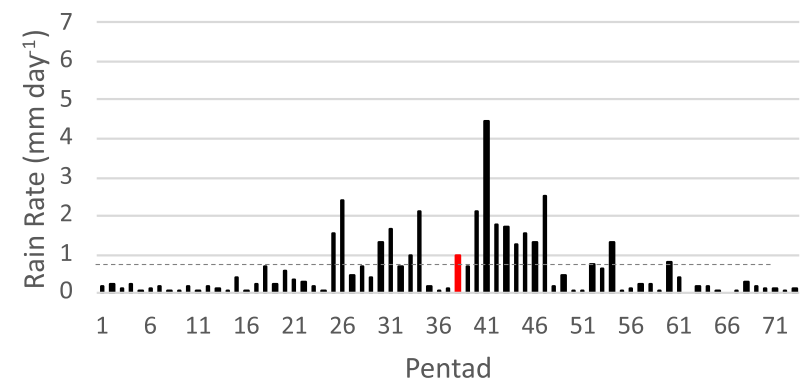

2010 IPF, Box13

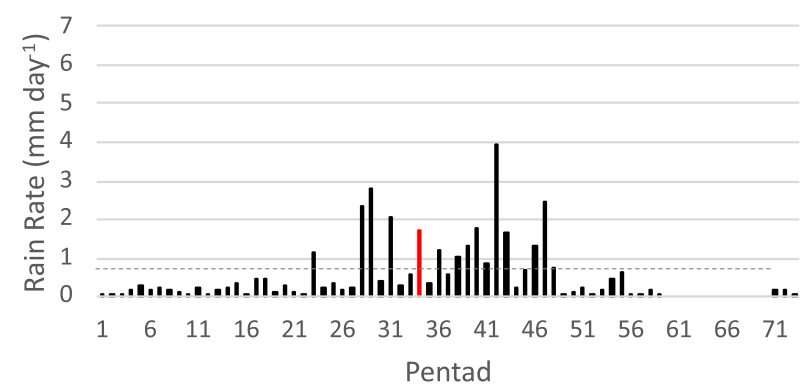

2011 IPF, Box13

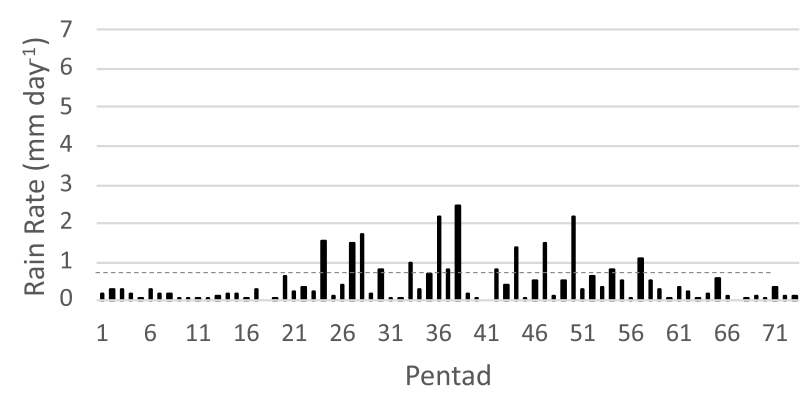

2012 IPF, Box13

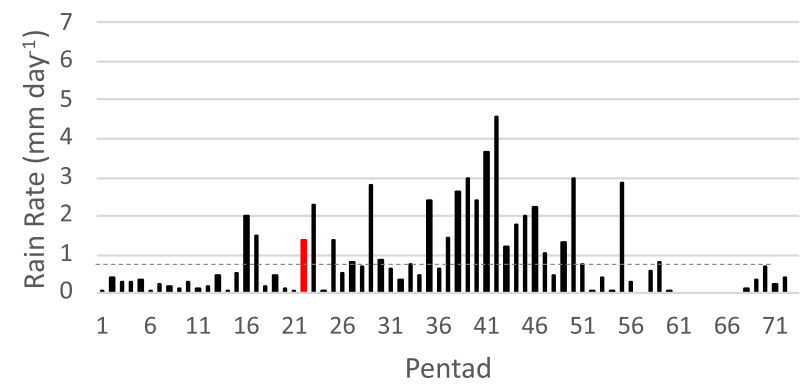

FIG. 12. As in Fig. 10, but for box 13 (central North Carolina in the southeastern coastal plain).

triggered only in 2 of the 4 years. For most years in box 2, IPF rain tends to occur in events lasting 1-3 pentads, spread fairly evenly throughout the spring and summer period. Only 2010 shows a summer maximum
2009 IPF, Box2

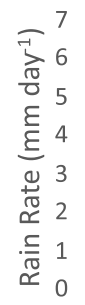

$\begin{array}{lllllllllllllll}1 & 6 & 11 & 16 & 21 & 26 & 31 & 36 & 41 & 46 & 51 & 56 & 61 & 66 & 71\end{array}$

2010 IPF, Box2

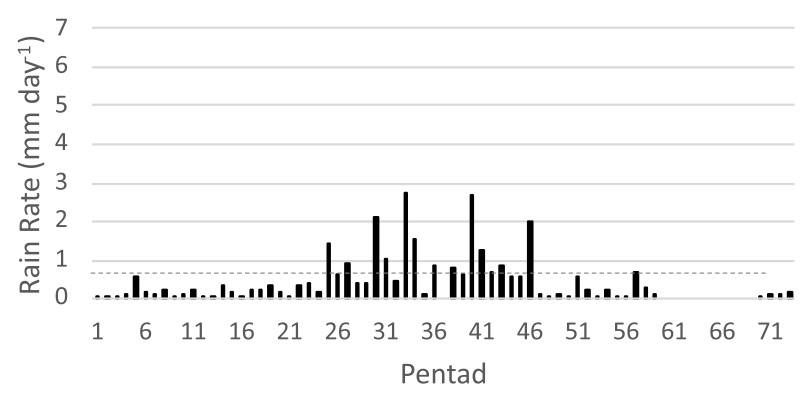

2011 IPF, Box2

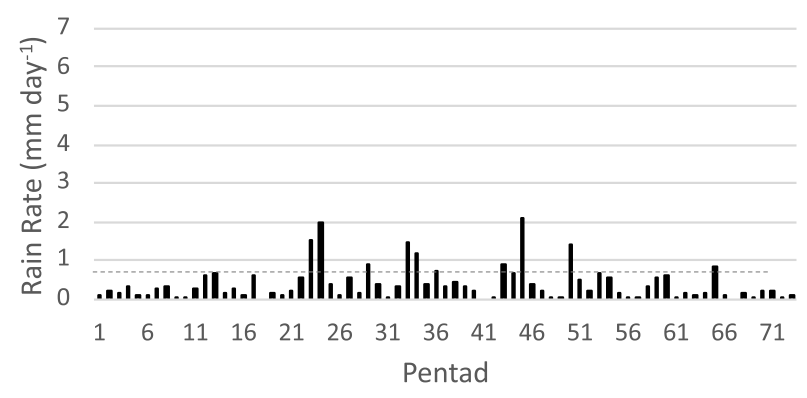

2012 IPF, Box2

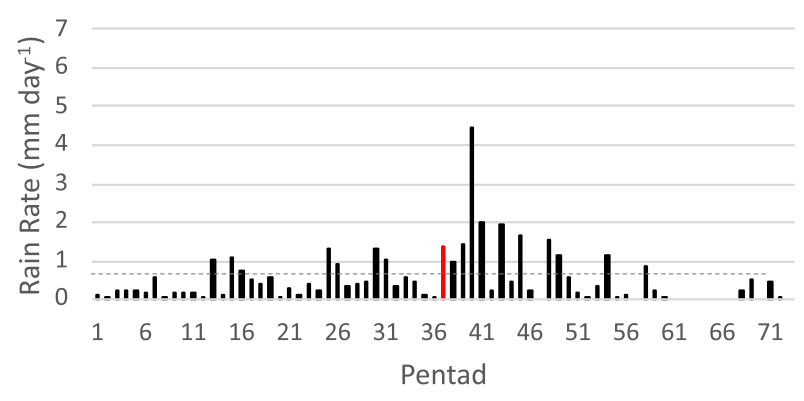

FIG. 13. As in Fig. 10, but for box 2 (Ohio Valley in the northwestern domain).

clearly defined in time. In summary, for the northern boxes the general trend was for less IPF rain, more variable IPF rain, and less of a clear summer maximum. The southern boxes had a more clearly 
defined onset, with more and sustained IPF rain in the summer season.

\section{Summary and conclusions}

This study examines the geographic and temporal characteristics of the spring-to-summer transition of the isolated convection (IPF) rain regime in the SE United States, using a methodology that is traditionally used for determining monsoon onset. The IPF rain is extracted from 4 years (2009-12) of a high-resolution surface radar precipitation dataset, and combined with an objective method of determining onset to evaluate the timing, geographic progression, spatial variability, and year-toyear changes of the onset of the summer IPF rain regime. Pentad-averaged time series of IPF rain in thirty-four $2^{\circ} \times 2^{\circ}$ boxes across the SE U.S. domain are constructed from south Florida, the southern and southeastern coastal plain, and northward to the Ohio Valley.

A clear summer (JJA) maximum in IPF rain occurs each year, with a year-to-year variation of about $30 \%$ in domain-averaged IPF rain. The overall IPF onset for the four-year mean over the entire SE U.S. domain occurs at pentad 27 (late May). In mid-April onset begins in south Florida, then is established quickly and widely across the southeastern coastal plain in early to mid-May. Farther to the north, the timing of onset is spatially and temporally variable. From year to year, the southern domain (Florida and the coastal plain) has a more consistent onset timing than other regions. Each year, onset for the SE U.S. domain as a whole occurs in May, ranging from pentad 25 (early May) in 2009 to pentad 30 (late May) in 2011. The years 2009 and 2010 are quite similar in the geographic pattern of onset timing, as well as the sharp and marked increase of IPF rain at onset. In those years, onset begins broadly across the southern and southeastern coastal plain during early to mid-May. Compared to the coastal plain, IPF rain onset in the Florida panhandle occurs two pentads earlier in 2010 and two pentads later in 2009. In 2011, onset is established simultaneously across the southern coastal plain in early to mid-June, about five pentads later than in 2009 and 2010. The onset timing and pattern in 2012 for the southern coastal plain is similar to 2009 , but highly variable in the rest of the SE U.S. domain.

Several aspects of onset are consistent each year. The post- minus preonset IPF rain difference for the threemonth mean prior to and following onset (related to the amplitude of the seasonal cycle) shows a remarkable consistency, with the largest post- minus preonset difference in Florida, decreasing northward to the coastal plain, and smallest differences in the northern domain. Time series for the southern boxes generally show a sharper and more sudden IPF rain onset. In each year the onset pentad is consistently later in the northern domain, with onset dates from mid-June to early July.

In summary, though the IPF rain onset in the SE United States shares some characteristics with the framework of monsoon onset, there are important contrasts. For the region as a whole, IPF onset occurs each of the 4 years within the month of May, which aligns with the seasonal consistency of regional onset timing in the monsoon. However, unlike a monsoon, IPF onset does not orderly progress poleward with time; rather, it tends to occur earlier in southern Florida, then simultaneously across a wide region of the coastal plain, and with large time and space variability in the northern part of the SE U.S. domain. There are year-to-year differences in IPF onset timing, and regionally IPF rain tends to rise and fall over several pentads, similar behavior as the interannual variability of monsoon onset and the existence of intraseasonal variations with 'active' and 'break' periods during the monsoon season.

These results suggest the hypothesis that IPF onset timing may be triggered by specific synoptic-scale events within gradual seasonal changes in atmospheric conditions including extratropical cyclone tracks, convective instability, and the westward migration of the North Atlantic subtropical high. This hypothesis will be evaluated in a forthcoming study of the mechanisms that control the geographic and year-to-year variability of isolated convection precipitation onset. The present study is considered preliminary due to the limited fouryear analysis period. As a longer archive of MRMS precipitation data become available we will extend the analysis to up to 15 years to develop better statistics on IPF onset and provide a more robust result. Ultimately, this approach may offer a useful framework for evaluating long-term changes in precipitation (past and future) for the SE United States and other mixed subtropical regimes in an observational and modeling context.

Acknowledgments. This study was funded by a grant (AGS-1660049) from the National Science Foundation's Climate and Large-Scale Dynamics program. We very much appreciate the useful suggestions of the reviewers, which greatly improved the manuscript.

\section{REFERENCES}

Brooks, H. E., and D. J. Stensrud, 2000: Climatology of heavy rain events in the United States from hourly precipitation observations. Mon. Wea. Rev., 128, 1194-1201, https://doi.org/ 10.1175/1520-0493(2000)128<1194:COHREI >2.0.CO;2.

Byers, H. R., and R. R. Braham, 1948: Thunderstorm structure and circulation. J. Meteor., 5, 71-86, https://doi.org/10.1175/15200469(1948)005<0071:TSAC $>2.0 . \mathrm{CO} ; 2$. 
Carbone, R. E., and J. Tuttle, 2008: Rainfall occurrence in the U.S. warm season: The diurnal cycle. J. Climate, 21, 4132-4146, https://doi.org/10.1175/2008JCLI2275.1.

- J. D. Tuttle, D. A. Ahijevych, and S. B. Trier, 2002: Inferences of predictability associated with warm season precipitation episodes. J. Atmos. Sci., 59, 2033-2056, https://doi.org/10.1175/ 1520-0469(2002)059<2033:IOPAWW >2.0.CO;2.

Carvalho, L. M. V., and C. Jones, 2001: A satellite method to identify structural properties of mesoscale convective systems based on the maximum spatial correlation tracking technique (MASCOTTE). J. Appl. Meteor., 40, 1683-1701, https://doi.org/ 10.1175/1520-0450(2001)040<1683:ASMTIS>2.0.CO;2.

Curtis, S., 2006: Developing a climatology of the south's 'other' storm season: ENSO impacts on winter extratropical cyclogenesis. Southeast. Geogr., 46, 231-244, https://doi.org/ 10.1353/sgo.2006.0021.

Fabry, F., V. Meunier, B. P. Tresarras, A. Cournoyer, and B. Nelson, 2017: On the climatological use of radar data mosaics: Possibilities and challenges. Bull. Amer. Meteor. Soc., 98, 2135-2148, https://doi.org/10.1175/BAMS-D-15-00256.1.

Fasullo, J., and P. J. Webster, 2003: A hydrological definition of Indian monsoon onset and withdrawal. J. Climate, 16 3200-3211, https://doi.org/10.1175/1520-0442(2003)016<3200a: AHDOIM $>2.0 . \mathrm{CO} ; 2$

Feng, Z., R. A. Houze Jr., L. Leung, F. Song, J. Hardin, J. Wang, W. Gustafson, and C. Homeyer, 2019: Spatiotemporal characteristics and large-scale environments of mesoscale convective systems east of the Rocky Mountains. J. Climate, 32 7303-7328, https://doi.org/10.1175/JCLI-D-19-0137.1.

Gamble, D. W., D. B. Parnell, and S. Curtis, 2008: Spatial variability of the Caribbean mid-summer drought and relation to North Atlantic high circulation. Int. J. Climatol., 28, 343-350, https://doi.org/10.1002/joc. 1600 .

Garreaud, R., 2000: Cold air incursions over subtropical South America: Mean structure and dynamics. Mon. Wea. Rev., 128, 2544-2559, https://doi.org/10.1175/1520-0493(2000)128<2544: CAIOSS $>2.0 . \mathrm{CO} ; 2$.

Geerts, B., 1998: Mesoscale convective systems in the southeast United States during 1994-95: A survey. Wea. Forecasting, 13, 860-869, https://doi.org/10.1175/1520-0434(1998)013<0860: MCSITS $>2.0 . \mathrm{CO} ; 2$.

Giannini, A., Y. Kushnir, and M. A. Cane, 2000: Interannual variability of Caribbean rainfall, ENSO, and the Atlantic Ocean. J. Climate, 13, 297-311, https://doi.org/10.1175/1520-0442(2000) 013<0297:IVOCRE $>2.0$. CO;2.

Haberlie, A. M., and W. S. Ashley, 2019: A radar-based climatology of mesoscale convective systems in the United States. J. Climate, 32, 1591-1606, https://doi.org/10.1175/ JCLI-D-18-0559.1.

Harrold, T., 1973: Mechanisms influencing the distribution of precipitation within baroclinic disturbances. Quart. J. Roy. Meteor. Soc., 99, 232-251, https://doi.org/10.1002/qj.49709942003.

Henderson, K. G., and A. J. Vega, 1996: Regional precipitation variability in the Southern United States. Phys. Geogr., 17, 93-112, https://doi.org/10.1080/02723646.1996.10642576.

Houze, R. A., Jr., 1989: Observed structure of mesoscale convective systems and implications for large-scale heating. Quart. J. Roy. Meteor. Soc., 115, 425-461, https://doi.org/10.1002/ QJ.49711548702.

Larson, J., Y. Zhou, and R. W. Higgins, 2005: Characteristics of landfalling tropical cyclones in the United States and Mexico: Climatology and interannual variability. J. Climate, 18, 1247-1262, https://doi.org/10.1175/JCLI3317.1.
Lau, K. M., and S. Yang, 1997: Climatology and interannual variability of the southeast Asian summer monsoon. Adv. Atmos. Sci., 14, 141-162, https://doi.org/10.1007/s00376-997-0016-y.

Leary, C., and R. A. Houze Jr., 1979: The structure and evolution of convection in a tropical cloud cluster. J. Atmos. Sci., 36, 437-457, https://doi.org/10.1175/1520-0469(1979)036<0437: TSAEOC $>2.0 . \mathrm{CO} ; 2$.

Li, L., W. Li, and Y. Kushnir, 2011: Variation of the North Atlantic subtropical high western ridge and its implication to Southeastern U.S. summer precipitation. Climate Dyn., 39, 1401-1412, https://doi.org/10.1007/s00382-011-1214-y.

- R. W. Schmitt, and C. C. Ummenhofer, 2017: The role of the subtropical North Atlantic water cycle in recent U.S. extreme precipitation events. Climate Dyn., 50, 1291-1305, https:// doi.org/10.1007/s00382-017-3685-y.

Liebmann, B., and J. A. Marengo, 2001: Interannual variability of the rainy season and rainfall in the Brazilian Amazon basin. J. Climate, 14, 4308-4318, https://doi.org/10.1175/ 1520-0442(2001)014<4308:IVOTRS > 2.0.CO;2.

Machado, L. A. T., W. B. Rossow, R. L. Guedes, and A. W. Walker, 1998: Life cycle variations of mesoscale convective systems over the Americas. Mon. Wea. Rev., 126, 1630-1654, https://doi.org/ 10.1175/1520-0493(1998)126<1630:LCVOMC > 2.0.CO;2.

Maddox, R. A., and C. A. Doswell, 1982: An examination of jet stream configurations, $500 \mathrm{mb}$ vorticity advection, and low-level thermal advection patterns during extended periods of intense convection. Mon. Wea. Rev., 110, 184-197, https://doi.org/ 10.1175/1520-0493(1982)110<0184:AEOJSC > 2.0.CO;2.

Marengo, J. A., B. Liebmann, V. E. Kousky, N. P. Filizola, and I. Wainer, 2001: Onset and end of the rainy season in the Brazilian Amazon basin. J. Climate, 14, 833-852, https://doi.org/ 10.1175/1520-0442(2001)014<0833:OAEOTR $>2.0$. CO;2.

Miller, P. W., and T. L. Mote, 2017: A climatology of weakly forced and pulse thunderstorms in the southeast United States. J. Appl. Meteor. Climatol., 56, 3017-3033, https://doi.org/ 10.1175/JAMC-D-17-0005.1.

Nesbitt, S. W., E. J. Zipser, and D. J. Cecil, 2000: A census of precipitation features in the tropics using TRMM: Radar, ice scattering, and lightning observations. J. Climate, 13, 4087-4106, https://doi.org/10.1175/1520-0442(2000)013<4087: ACOPFI > 2.0.CO;2.

Nieto-Ferreira, R., and T. M. Rickenbach, 2011: Regionality of monsoon onset in South America: A three-stage conceptual model. Int. J. Climatol., 31, 1309-1321, https://doi.org/ 10.1002/joc. 2161 .

— L. Hall, and T. M. Rickenbach, 2013: A climatology of the structure, evolution and propagation of midlatitude cyclones in the southeast United States. J. Climate, 26, 8406-8421, https://doi.org/10.1175/JCLI-D-12-00657.1.

NOAA/NCEI, 2019: Climate at a glance: Regional precipitation time series. Accessed 3 August 2019, https://www.ncdc.noaa.gov/cag.

Noska, R., and V. Misra, 2016: Characterizing the onset and demise of the Indian summer monsoon. Geophys. Res. Lett., $\mathbf{4 3}$, 4547-4554, https://doi.org/10.1002/2016GL068409.

Raia, A., and I. F. Cavalcanti, 2008: The life cycle of the South American monsoon system. J. Climate, 21, 6227-6246, https:// doi.org/10.1175/2008JCLI2249.1.

Ramage, C., 1971: Monsoon Meteorology. International Geophysics Series, Vol. 15, Academic Press, 296 pp.

Rasp, S., T. Selz, and G. C. Craig, 2016: Convective and slantwise trajectory ascent in convection-permitting simulations of midlatitude cyclones. Mon. Wea. Rev., 144, 3961-3976, https:// doi.org/10.1175/MWR-D-16-0112.1. 
Rickenbach, T. M., R. Nieto-Ferreira, R. Barnhill, and S. Nesbitt, 2011: Regional contrast of mesoscale convective system structure prior to and during monsoon onset across South America. J. Climate, 24, 3753-3763, https://doi.org/10.1175/ 2011JCLI3975.1.

, _ _ C. Zarzar, and B. Nelson, 2015: A seasonal and diurnal climatology of precipitation organization in the Southeastern United States. Quart. J. Roy. Meteor. Soc., 141, 1938-1956, https://doi.org/10.1002/qj.2500.

Ropelewski, C. F., and M. S. Halpert, 1986: North American precipitation and temperature patterns associated with the El Niño/Southern Oscillation (ENSO). Mon. Wea. Rev., 114, 2352-2362, https://doi.org/10.1175/1520-0493(1986)114<2352: NAPATP $>2.0 . \mathrm{CO} ; 2$.

Wallace, J. M., 1975: Diurnal variations in precipitation and thunderstorm frequency over the conterminous United States. Mon. Wea. Rev., 103, 406-419, https://doi.org/10.1175/15200493(1975)103<0406:DVIPAT > 2.0.CO;2.

Winkler, J. A., B. R. Skeeter, and P. D. Yamamoto, 1988: Seasonal variations in the diurnal characteristics of heavy hourly precipitation across the United States. Mon. Wea.
Rev., 116, 1641-1658, https://doi.org/10.1175/1520-0493(1988) $116<1641:$ SVITDC $>2.0$. CO;2.

Yihui, D., and J. C. Chan, 2005: The East Asian summer monsoon: An overview. Meteor. Atmos. Phys., 89, 117-142, https:// doi.org/10.1007/s00703-005-0125-z.

Zhang, J., and Coauthors, 2011: National Mosaic and Multi-Sensor QPE (NMQ) system: Description, results, and future plans. Bull. Amer. Meteor. Soc., 92, 1321-1338, https://doi.org/ 10.1175/2011BAMS-D-11-00047.1.

Zhou, Y., and C. J. Matyas, 2017: Spatial characteristics of stormtotal rainfall swaths associated with tropical cyclones over the Eastern United States. Int. J. Climatol., 37, 557-569, https:// doi.org/10.1002/joc.5021.

Zhu, J., and X. Liang, 2013: Impacts of the Bermuda high on regional climate and ozone over the United States. J. Climate, 26, 1018-1032, https://doi.org/10.1175/JCLI-D-12-00168.1.

Zishka, K. M., and P. J. Smith, 1980: The climatology of cyclones and anticyclones over North America and surrounding ocean environs for January and July, 1950-77. Mon. Wea. Rev., 108, 387-401, https://doi.org/10.1175/1520-0493(1980)108<0387: TCOCAA $>2.0 . C O ; 2$. 